\title{
Convenient method of peptide hydrazide synthesis using a new hydrazone resin
}

\author{
Thomas Bruckdorfer ${ }^{1}$, Pavel S. Chelushkin ${ }^{2}$, Ksenia V. Polyanichko², Maria Leko ${ }^{2}$, Marina Dorosh $^{2}$, Sergey V. Burov $^{2}$ \\ ${ }^{1}$ Iris Biotech GmbH, Germany \\ ${ }^{2}$ Institute of Macromolecular Compounds, St. Petersburg State University, Russia
}

https://doi.org/10.17952/35EPS.2018.084

\section{Introduction}

Peptide hydrazides are useful building blocks for the synthesis of conjugates with different carrier molecules such as proteins, dendrimers and polymers[1-3]. Attachment of peptide vectors by means of hydrazone ligation is widely applied for the design of targeted drug delivery systems. Recently it was shown that peptide hydrazides can be easily converted to corresponding isocyanates or thioesters[4,5]. These reactive species are especially useful for the conjugation with different nucleophiles, peptide cyclisation and synthesis of proteins using chemical ligation approach.

Hydrazinolysis of peptide esters can be accompanied by the formation of side products while their solid phase synthesis commonly demands application of rather expensive starting materials and/or multistage synthetic procedure. Previously we described simple synthetic protocol based on the acylation of aminomethyl polystyrene resin by the Fmoc-protected hydrazone of pyruvic acid[6]. In this study we present the optimized loading protocol and application of novel resin for the synthesis of linear and branched peptides.

\section{Results and Discussion}

The ability of pyruvic acid to form relatively stable hydrazones in reasonable yields determines their utility as anchoring groups for peptide hydrazides synthesis using $\mathrm{Fmoc} / \mathrm{Bu}^{\mathrm{t}}$ strategy. Aminomethyl polystyrene (AMPS) resin, widely applied for solid phase synthesis, seems to be a cheap and convenient starting material for subsequent modification.

Investigation of different protocols for the synthesis of hydrazone resin has shown the utility of AMPS polymer acylation by the Fmoc-hydrazone of pyruvic acid. Attachment of a preformed hydrazone linker ensures high loading level along with the possibility of its control by UV spectroscopy at the stage of Fmoc group removal.

It should be mentioned that attachment of the first amino acid using different coupling agents (DIC, HCTU or SA) is accompanied by partial loss of polymer capacity. These results cannot be explained by incomplete acylation or partial decomposition of the hydrazone resin and the nature of this process is not completely clear.

In the course of loading protocol optimization it was shown that application of high capacity AMPS resin $(1.2 \mathrm{mmol} / \mathrm{g}$ ) permits to achieve the desirable loading level (up to $0.9 \mathrm{mmol} / \mathrm{g}$ ) using only 1 eqv of acylating agent. However, the standard procedure of residual amino groups capping ( $\mathrm{Ac}_{2} \mathrm{O} / \mathrm{DIEA}$ ) seems to be inefficient. Moreover, acetylation in DMF resulted in remarkable decrease of loading level. An optimized capping protocol presumes application of $\mathrm{Ac}_{2} \mathrm{O} / \mathrm{DIEA} / \mathrm{DCM}$ mixture and acetylation in swelling volume during 1-2 $\mathrm{h}$.

Attachment of the first amino acid demands thorough control of acylation completeness and proper selection of reaction conditions. In general, HCTU coupling increases the acylation yield, especially in the case of bulky amino acid derivatives as compared to DIC/Cl-HOBt protocol. 


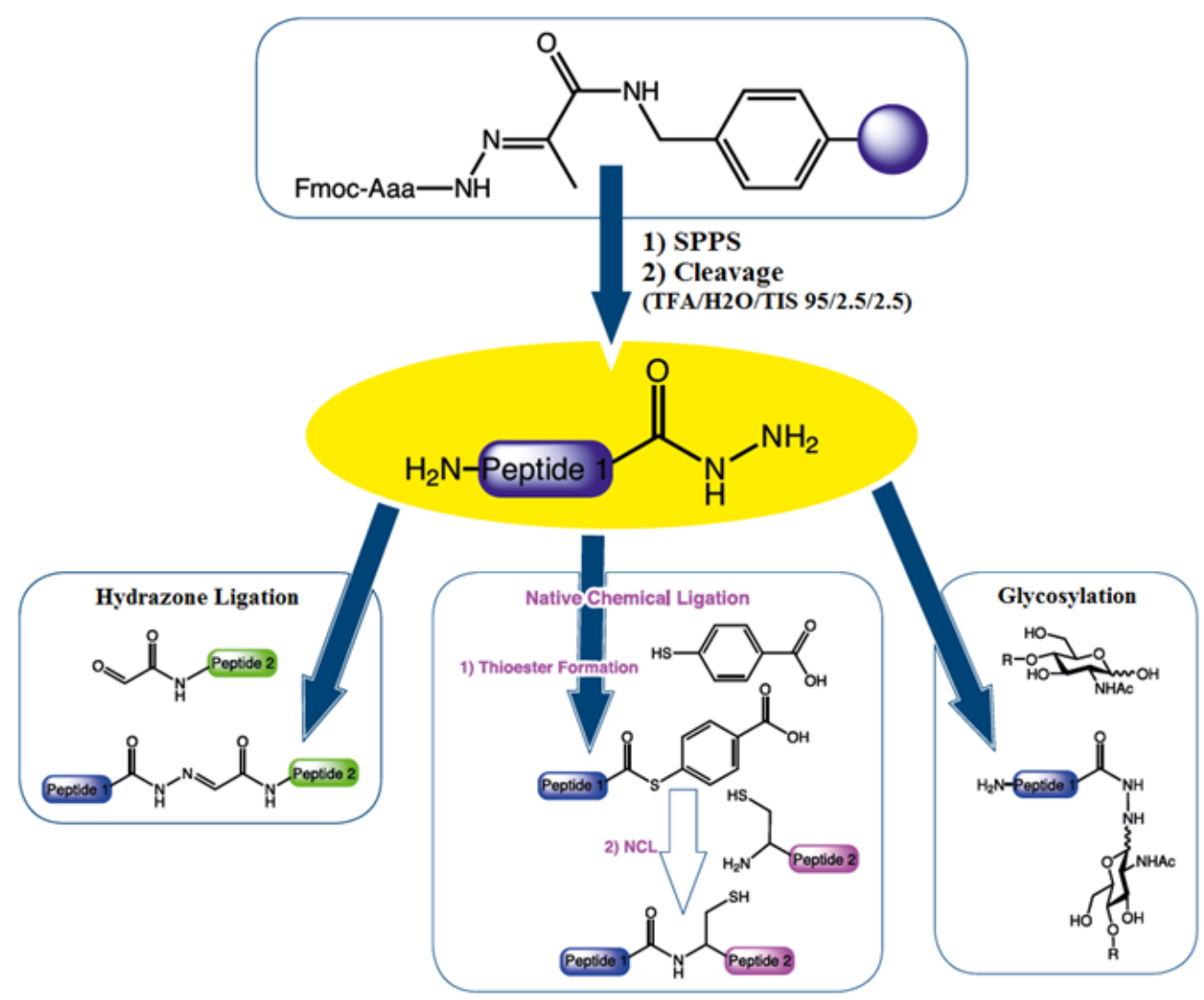

Figure 1: Application of hydrazone resin.

It was shown that the hydrazone bond is completely stable in the course of Fmoc group removal and DIC mediated coupling in the presence of acidic additives such as HOBt. Moreover, it is tolerant to treatment with $5 \%$ TFA/DCM for $3 \mathrm{~h}$ thus permitting selective removal of $\mathrm{Mtt}$ and related acid-labile groups.

To verify the possibility of selective Mtt deprotection we synthesized model peptide sequence: Fmoc-Arg(Pbf)Gly-Asp(OBut)-D-Phe-Lys(Mtt) attached to the hydrazone resin. Then Mtt group was removed by repeating treatment with 5\% TFA and 5\% TIS in DCM ( $5 \times 2 \mathrm{~min})$. Subsequent acylation of the $\varepsilon$-amino group with 5(6)-carboxyfluorescein (Flu) followed by cleavage/deprotection procedure resulted in the desired peptide: $\mathrm{H}$-Arg-Gly-Asp-D-Phe-Lys(Flu) $-\mathrm{N}_{2} \mathrm{H}_{3}$.

The practical utility of the suggested resin was proved by the synthesis of different peptides including the nuclear localization signal (NLS) of large T-antigen of SV-40 virus, tuftsin, Szeto-Schiller peptide, and building blocks for the design of self-assembling biomaterials containing RADA units. 


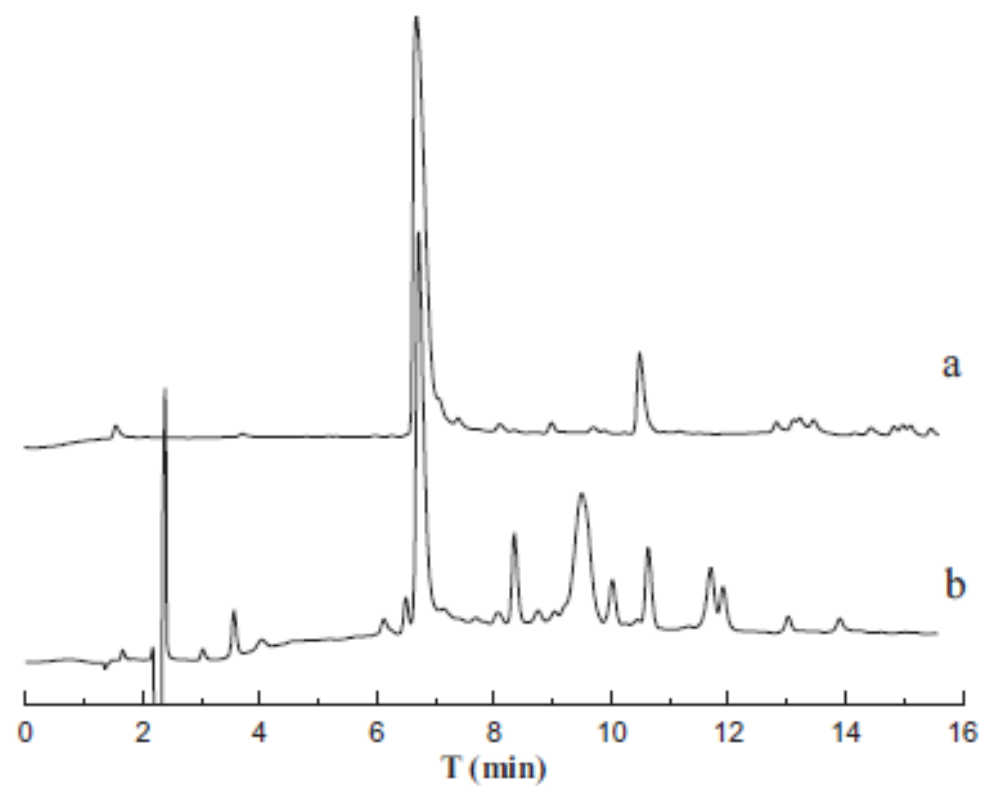

Figure 2: RP-HPLC analysis of crude NLS hydrazide synthesized using hydrazone resin (a) and protected peptide precursor $(b)$.

The advantages of new resin can be illustrated by the synthesis of NLS hydrazide as compared to HCTU-mediated acylation of BOC-hydrazide by protected peptide precursor synthesized on Cl-Trt polymer (Fig. 2). It should be mentioned that application of hydrazone resin permits to improve both purity of crude peptide and the yield of final product (55\% as compared to $19 \%$ in the case of BOC-hydrazide acylation).

In conclusion, the suggested approach permits to prepare peptide building blocks containing a hydrazide group useful for the conjugation with different carrier molecules using hydrazone ligation technique.

\section{References}

1. Brunel F.M., Lewis J.D., Destito G., Steinmetz N.F., Manchester M., Stuhlmann H., Dawson P.E.

Nano Lett. 2010, 10, 10931097. DOI: 10.1021/nl1002526.

2. Shao, J., Tam, J. P. J. Am. Chem. Soc. 1995, 117, 38933899. DOI: 10.1021/ja00119a001.

3. Gauthier M.A., Klok H.-A. Chem. Commun. 2008, 21, 2591-2611. DOI: 10.1039/b719689j.

4. Vinogradov, A.A., Simon, M.D., Pentelute B.L. Org. Lett. 2016, 18, 1222-1225.

DOI: 10.1021 /acs.orglett.5b03625.

5. Huang, Y.-C., Fang, G.-M., Liu L. Natl. Sci. Rev. 2016, 3, 107-116. DOI: 10.1093/nsr/nwv072.

6. Chelushkin P.S., Polyanichko K.V., Leko M.V., Dorosh M.Yu., Bruckdorfer T., Burov S.V.

TetrahedronLett. 2015, 56, 619-622. DOI: 10.1016/j.tetlet.2014.12.056. 